\title{
Corona-Puzzle, Hope and Challenging Trends in Treatment-Original Research Article
}

\author{
N. Suresh ${ }^{1}$, A. Karthikeyan ${ }^{2 *}$
}

${ }^{1} \mathrm{MD}$, Assistant professor, Department of Medicine, Govt. Theni Medical College, Kochi - Madurai - Dhanushkodi Rd, Theni Allinagaram, Tamil Nadu 625531, India

${ }^{2} \mathrm{MD}$, Assistant professor, Department of Medicine, Govt. Theni Medical College, Kochi - Madurai - Dhanushkodi Rd, Theni Allinagaram, Tamil Nadu 625531, India

DOI: $10.36347 /$ sajb.2021.v09i02.002

| Received: 20.01.2021 | Accepted: 28.01.2021 | Published: 06.02.2021

*Corresponding author: A. Karthikeyan

Abstract

Original Research Article

Severe acute respiratory syndrome coronavirus 2 (SARS-CoV-2), initially named novel coronavirus or 2019-nCoV, is a single-stranded RNA virus. Covid has been designated as pandemic by WHO. Adaptability and mutations of the virus made the treatment modalities difficult and complications even worsen. Human to human transmission is more in crowded areas, social and mass gathering and making the virulence more and more. Patients suffering from symptoms of like fever, cough, dyspnoea, myalgia, headache, and sore throat were considered who attended the OPD of medicine and other departments. Severity of clinical symptoms can vary between individuals. $81 \%$ of cases were described as mild (i.e. non-pneumonia and mild pneumonia). $14 \%$ of cases were severe (i.e. dyspnea, respiratory frequency $\geq 30 / \mathrm{min}$, blood oxygen saturation $\leq 93 \%$, partial pressure of arterial oxygen to fraction of inspired oxygen ratio $50 \%$ within $24-48$ h), and 5\% were critical (i.e. respiratory failure, septic shock, and/or multiple organ dysfunction or failure). Treatment depends on the supportive and invasive methods. Preventive measures are better modalities and still holds good to decrease the spread of coronavirus which includes handwash using sanitizers, N95 masks and spacing.

Keywords: Corona, adults, paediatric treatment modalities.

Copyright (C) 2021 The Author(s): This is an open-access article distributed under the terms of the Creative Commons Attribution 4.0 International License (CC BY-NC 4.0) which permits unrestricted use, distribution, and reproduction in any medium for non-commercial use provided the original author and source are credited.

\section{INTRODUCTION}

Severe acute respiratory syndrome coronavirus 2 (SARS-CoV-2), initially named novel coronavirus or 2019-nCoV, is a single-stranded RNA virus which forms one of the seven coronaviridae - 229E, OC43, NL63, HKU1, severe acute respiratory syndrome coronavirus (SARSCoV), and Middle East respiratory syndrome coronavirus (MERS-CoV) [1]. Coronavirus is being transmitted from human to human which is really bothering the medical fraternity. A type of lower respiratory tract infection with the potential to cause severe and possibly fatal atypical novel coronavirus (2019-nCoV)-infected pneumonia (NCIP) in humans [2-4].

\section{Prevalence and Mode of Transmission}

Covid has been designated as pandemic by WHO [5]. The most affected countries across the globe is USA followed by Spain and Italy where the mortality rate is high accounting for more than 1.7 lakh deaths.SARS-CoV-2, compared with SARS-CoV both viruses share an amino acid sequence similarity of $76.5 \%$ and utilise angiotensin-converting enzyme 2
(ACE2) receptors as a mode of entry into healthy cells. Variations between the receptor-binding domain of the two brought about by mutations [7], genetic recombination [8], and natural selection ${ }^{7}$ enable SARS-CoV-2 to bind to the receptor more effectively [6].

Adaptability and mutations of the virus made the treatment modalities difficult and complications even worsen. Human to human transmission is more in crowded areas, social and mass gathering and making the virulence more and more.

\section{Clinical Presentation}

The World Health Organisation (WHO) estimates that the incubation time from infection to presentation of symptoms is 5.2 days, with a range of $1-$ 14 days [9]. Based on computerised tomography (CT) findings and can be divided into early ( $0-4$ days), progressive (5-8 days), peak (9-13 days), and absorption stages ( $\geq 14$ days) [10]. Early stage disease consists of subpleural ground glass opacities (GGO) located in the lower lung lobes. 
Severity of clinical symptoms can vary between individuals. $81 \%$ of cases were described as mild (i.e. non-pneumonia and mild pneumonia). $14 \%$ of cases were severe (i.e. dyspnea, respiratory frequency $\geq 30 /$ min, blood oxygen saturation $\leq 93 \%$, partial pressure of arterial oxygen to fraction of inspired oxygen ratio $50 \%$ within $24-48 \mathrm{~h}$ ), and $5 \%$ were critical (i.e. respiratory failure, septic shock, and/or multiple organ dysfunction or failure) [11].

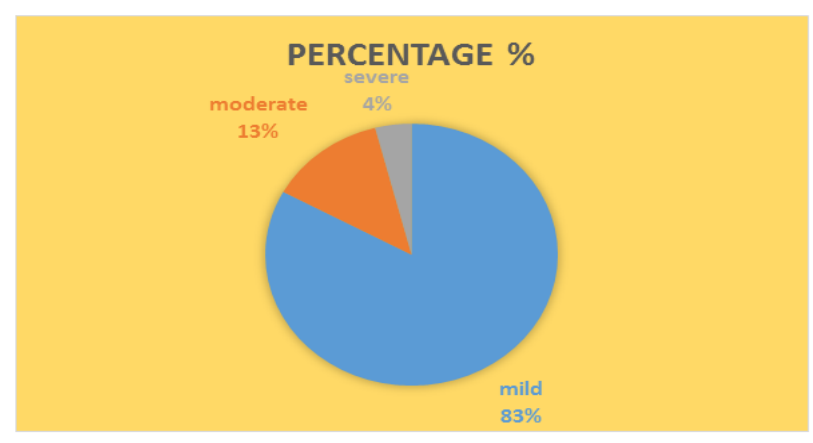

\section{MATERIALS AND METHOD}

Patients suffering from symptoms of like fever, cough, dyspnoea, myalgia, headache, and sore throat were considered who attended the OPD of medicine and other departments also in Theni medical college and these patients were sent for diagnostic tests. Few of them were admitted in the hospital. Lymphopenia was the most common laboratory finding among people with COVID-19, and is found in up to $83 \%$ of hospitalized patients [12, 13]. Lymphopenia, neutrophilia, elevated serum alanine aminotransferase, aspartate aminotransferase levels, elevated lactate dehydrogenase, high C-reactive protein (CRP), and high ferritin levels were observed with greater illness severity [12-15]. In the paediatric population, symptoms may include fever, nasal congestion, runny nose, expectoration, fatigue, cough, diarrhoea, and headache. As the disease progresses, signs of dyspnoea, cyanosis, in addition to systemic toxic symptoms, including malaise or restlessness, poor feeding, bad appetite and reduced activity may also present. In the most severe situations, these younger patients may progress into respiratory failure unresponsive to conventional oxygen therapy, septic shock, metabolic acidosis, irreversible bleeding, and coagulation dysfunction [16].

Mild uncomplicated illnesses include non-specific symptoms including fever, cough, sore throat, nasal congestion, headache, and muscle pain. Elderly and immunosuppressed individuals presented with atypical findings. Patients with high blood glucose levels and high blood pressure were vulnerable.

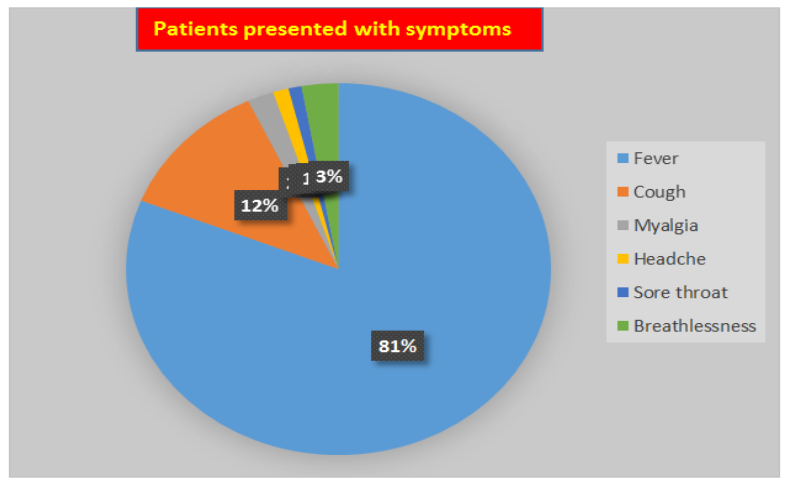

\section{Prevention}

Corona virus prevention can be done by the following remedies;

1. Case isolation in home

2. Voluntary home quarantine

3. Social distancing in elderly persons

4. Social distancing for the entire population

5. Closure of densely populated area

6. Closure of schools

Even after taking treatment one should maintain social distancing.

Management: Treatment depends on the supportive and invasive methods.

Mild: supportive and symptomatic therapy.

\section{Intravenous (IV) Fluid Administration Oxygen Therapy}

- If patients present with SARI, hypoxemia or shock $5 \mathrm{~L} / \mathrm{min}$ to reach target $\mathrm{SpO} 2$ of at least $90 \%$ in non-pregnant adults (over $92 \%$ in pregnant patients).

- Children with severe breathing difficulties should have a target $\mathrm{SpO} 2$ of over $94 \%$.

- Closely monitor patients with SARI in case of rapid respiratory failure or sepsis and intervene immediately. Clinicians should consider mechanical ventilation at this.

\section{Corticosteroids}

- Routinely administer corticosteroids in the treatment of viral pneumonia unless in a clinical trial or if steroids are indicated for another condition.

- Their use in studies on influenza have been found to exacerbate the infection and increase mortality rates [17].

Continuous positive airway pressure (CPAP) usage was seen more in the pandemic period as non-invasive procedure.

Endotracheal intubation: Preoxygenation for patients to combat the oxygen levels prior to infection 
N. Suresh \& A. Karthikeyan., Sch Acad J Biosci, Feb, 2021; 9(2): 25-28

Invasive mechanical ventilation: Titration of positive end-expiratory pressure (PEEP) should be guided by the Fraction of Inspired Oxygen (Fi02) required to achieve a desired arterial oxygen saturation (Sp02).

\section{Extracorporeal membrane oxygenation (ECMO) Fluid Resuscitation and Vasopressors}

In adults, fluid resuscitation should be administered as 250-500 $\mathrm{ml}$ crystalloid fluid boluses over 15-30 min followed by assessment for fluid overload after each bolus, norepinephrine is the drug of choice, which can be supplemented by epinephrine or vasopressin to maintain MAP targets. In children, fluid resuscitation should be administered as $10-20 \mathrm{~mL} / \mathrm{kg}$ crystalloid fluid boluses over 30-60 min followed by assessment for fluid overload after each bolus.

\section{Antiviral Drugs}

Mainly ramdesivir has been successfully used in the mild to moderate stages. Chloroquine was used in the initial mild stage of infection. Apart from the above modalities of treatment latest injectable like covaxin and coshield is being used.

\section{CONCLUSION}

Preventive measures are better modalities and still holds good to decrease the spread of coronavirus which includes handwash using sanitizers, N95 masks and spacing.

\section{Interest of Conflict: Nil}

\section{REFERENCES}

1. Zhu N, Zhang D, Wang W, Li X, Yang B, Song J, Zhao X, Huang B, Shi W, Lu R, Niu P. A novel coronavirus from patients with pneumonia in China, 2019. New England journal of medicine. 2020 Jan 24.

2. Sohrabi C, Alsafi Z, O'Neill N, Khan M, Kerwan A, Al-Jabir A, Iosifidis C, Agha R. World Health Organization declares global emergency: A review of the 2019 novel coronavirus (COVID-19). International journal of surgery. $2020 \mathrm{Apr}$ 1;76:71-6.

3. Young BE, Ong SW, Kalimuddin S, Low JG, Tan SY, Loh J, Ng OT, Marimuthu K, Ang LW, Mak TM, Lau SK. Epidemiologic features and clinical course of patients infected with SARS-CoV-2 in Singapore. Jama. 2020 Apr 21;323(15):1488-94. Available from: http://www. ncbi.nlm.nih.gov/pubmed/32125362.

4. Early transmission dynamics in Wuhan, China, of novel coronavirus-infected pneumonia, NEJM, [Internet]. [cited 2020 Mar 9]. Available from: https://www. nejm.org/doi/full/10.1056/NEJMoa2001316.

5. BBC News [Internet], Coronavirus confirmed as pandemic, (2020 Mar 11) [cited 2020 Mar 11]; Available from: https://www.bbc.com/news/world-51839944
6. Zhang H, Penninger JM, Li Y, Zhong N, Slutsky AS. Angiotensin-converting enzyme 2 (ACE2) as a SARS-CoV-2 receptor: molecular mechanisms and potential therapeutic target. Intensive care medicine. $2020 \mathrm{Apr}$;46(4):586-90.

7. Tang X, Wu C, Li X, Song Y, Yao X, Wu X, Duan Y, Zhang H, Wang Y, Qian Z, Cui J. On the origin and continuing evolution of SARS-CoV-2. National Science Review. 2020 Jun 1;7(6):1012-23. Available from: https://academic.oup.com/nsr/advance-article/doi/ 10.1093/nsr/nwaa036/ 5775463

8. Yi H. 2019 novel coronavirus is undergoing active recombination. Clinical Infectious Diseases. 2020 Jul 28;71(15):884-7. Available from: http://www. ncbi.nlm.nih.gov/pubmed/32130405.

9. Q\&A on coronaviruses (COVID-19), [Internet]. [cited 2020 Mar 9]. Available from: https://www.who.int/news-room/q-a-detail/q-a-cor onaviruses

10. Zhu Y, Gao ZH, Liu YL, Xu DY, Guan TM, Li ZP, Kuang JY, Li XM, Yang YY, Feng ST. Clinical and CT imaging features of 2019 novel coronavirus disease (COVID-19). Journal of Infection. $2020 \mathrm{Jul}$ $1 ; 81(1): 147-78$.

11. Wu Z, McGoogan JM. Characteristics of and important lessons from the coronavirus disease 2019 (COVID-19) outbreak in China: summary of a report of 72314 cases from the Chinese Center for Disease Control and Prevention. Jama. 2020 Apr 7;323(13):1239-42.

12. Guan WJ, Ni ZY, Hu Y, Liang WH, Ou CQ, He JX, Liu L, Shan H, Lei CL, Hui DS, Du B. Clinical characteristics of coronavirus disease 2019 in China. New England journal of medicine. $2020 \mathrm{Apr}$ 30;382(18):1708-20.

13. Huang C, Wang Y, Li X, Ren L, Zhao J, Hu Y, Zhang L, Fan G, Xu J, Gu X, Cheng Z. Clinical features of patients infected with 2019 novel coronavirus in Wuhan, China. The lancet. $2020 \mathrm{Feb}$ 15;395(10223):497-506.

14. Wang D, Hu B, Hu C, Zhu F, Liu X, Zhang J, Wang B, Xiang H, Cheng Z, Xiong Y, Zhao Y. Clinical characteristics of 138 hospitalized patients with 2019 novel coronavirus-infected pneumonia in Wuhan, China. Jama. 2020 Mar 17;323(11):1061-9.

15. Wu C, Chen X, Cai Y, Zhou X, Xu S, Huang H, Zhang L, Zhou X, Du C, Zhang Y, Song J. Risk factors associated with acute respiratory distress syndrome and death in patients with coronavirus disease 2019 pneumonia in Wuhan, China. JAMA internal medicine. $2020 \mathrm{Jul} \mathrm{1;180(7):934-43.}$

16. Chen ZM, Fu JF, Shu Q, Chen YH, Hua CZ, Li FB, Lin R, Tang LF, Wang TL, Wang W, Wang YS. Diagnosis and treatment recommendations for pediatric respiratory infection caused by the 2019 novel coronavirus. World journal of pediatrics. 2020 Jun;16(3):240-6. 
N. Suresh \& A. Karthikeyan., Sch Acad J Biosci, Feb, 2021; 9(2): 25-28

17. Point Clinical management of severe acute respiratory infection when novel coronavirus (nCoV) infection is suspected, [Internet]. [Cited 2020 Mar 10]. Available from: https://www.who.int/publications-detail/clinical-m anagement-of-severe-acuterespiratory-infection-w hen-novel-coronavirus-(ncov)-infection-is-suspect ed. 